\title{
Effect of single-port inflatable mediastinoscopy simultaneous laparoscopic-assisted radical esophagectomy on respiration and circulation
}

\author{
Haibo Ye ${ }^{1,2}$, Xiaojin Wang ${ }^{1}$, Xiaojian $\mathrm{Li}^{1}$, Xiangfeng Gan ${ }^{1}$, Hongcheng Zhong ${ }^{1}$, Xiangwen $\mathrm{Wu}^{1{ }^{*}}$ and \\ Qingdong Cao ${ }^{1 *}$
}

\begin{abstract}
Background and purpose: We previously developed a new surgical method, namely, single-port inflatable mediastinoscopy simultaneous laparoscopic-assisted radical esophagectomy. The purpose of this study was to evaluate the effect of carbon dioxide inflation on respiration and circulation using this approach.

Methods: From April 2018 to October 2020, 105 patients underwent this novel surgical approach. The changes in respiratory and circulatory functions were reported when the mediastinal pressure and pneumoperitoneum pressure were 10 and $12 \mathrm{mmHg}$, respectively. Data on blood loss, operative time, and postoperative complications were also collected.

Results: 104 patients completed the operation successfully, except for 1 patient who was converted to thoracotomy because of intraoperative injury. During the operation, respectively, the heart rate, mean arterial pressure, central venous pressure, peak airway pressure, end-expiratory partial pressure of carbon dioxide and partial pressure of carbon dioxide increased in an admissibility range. The $\mathrm{pH}$ and oxygenation index decreased $1 \mathrm{~h}$ after inflation, but these values were all within a safe and acceptable range and restored to the baseline level after $\mathrm{CO}_{2}$ elimination. Postoperative complications included anastomotic fistula (8.6\%), pleural effusion that needed to be treated (8.6\%), chylothorax (0.9\%), pneumonia (7.6\%), arrhythmia (3.8\%) and postoperative hoarseness (18.2\%). There were no cases of perioperative death.

Conclusions: When the inflation pressure in the mediastinum and abdomen was $10 \mathrm{mmHg}$ and $12 \mathrm{mmHg}$, respectively, the inflation of carbon dioxide from single-port inflatable mediastinoscopy simultaneous laparoscopic-assisted radical esophagectomy did not cause serious changes in respiratory and circulatory function or increase perioperative complications.
\end{abstract}

Keywords: Esophagectomy, Inflatable mediastinoscopy, Circulation, Respiration

*Correspondence: yehb5@mail2.sysu.edu.cn; shijp13@lzu.edu.cn 1 Department of Thoracic Surgery, The Fifth Affiliated Hospital of Sun YatSen University, 52 East Meihua Road, Xiangzhou District, Zhuhai 519000, Guangdong, China

Full list of author information is available at the end of the article

\section{Introduction}

Esophageal cancer (EC) is one of the most common malignant tumors in the world, ranking seventh in global morbidity and sixth in mortality [1]. The prognosis of EC is poor, and the 5-year survival rate is less than $25 \%$ [2]. Currently, the basic treatment strategy original author(s) and the source, provide a link to the Creative Commons licence, and indicate if changes were made. The images or other third party material in this article are included in the article's Creative Commons licence, unless indicated otherwise in a credit line to the material. If material is not included in the article's Creative Commons licence and your intended use is not permitted by statutory regulation or exceeds the permitted use, you will need to obtain permission directly from the copyright holder. To view a copy of this licence, visit http://creativecommons.org/licenses/by/4.0/. The Creative Commons Public Domain Dedication waiver (http://creativeco mmons.org/publicdomain/zero/1.0/) applies to the data made available in this article, unless otherwise stated in a credit line to the data. 
for EC is a combination of surgery, radiotherapy and chemotherapy, and surgical treatment is still the main and preferred treatment [2,3]. Previous studies have shown that compared with open esophagectomy, minimally invasive esophagectomy (MIE) has the advantages of less postoperative pain, less intraoperative bleeding, shorter hospital stay and recovery time, and more extensive lymph node dissection. Thus, MIE has become the preferred surgical method [4-8].

The approaches of MIE are transthoracic and nontransthoracic (e.g., transhiatal esophagectomy). Transhiatal esophagectomy (THE) is considered to be less invasive and has fewer pulmonary complications because it avoids thoracotomy [9]. However, traditional THE has more stringent surgical indications because of its limited field of vision and insufficient mediastinal lymph node dissection, which is more suitable for cancers that indicate negative lymph nodes, and the oncology results are usually considered poor $[10,11]$. To overcome this shortcoming, Fujiwara et al. developed a new surgical method, namely, a radical resection of thoracic EC by using inflatable mediastinoscopic lymph node dissection through cervical incisions and hand-assisted laparoscopic lymph node dissection of the upper mediastinum, and this method has been reported to be safe and feasible [1214]. On this basis, our organization further improved the operation and carried out single-port inflatable mediastinoscopy simultaneous laparoscopic radical esophagectomy (SPIMSLE) [15].Our team improved this operation as following differences: first, our team is divided into mediastinal group and abdominal group to operate at the same time, and the operation time is significantly shortened; second, our abdominal group is operated completely under laparoscopy. rather than hand-assisted laparoscopic surgery, the trauma is less. Third, we have performed lymph node dissection of the right vagus nerve and the right recurrent laryngeal nerve through the left cervical incision [16].

In this procedure, we inflated the mediastinum and abdomen to provide a clear field of view for esophagectomy and mediastinal lymph node dissection. This operation, which is a relatively new surgical method, is not performed through the chest or onelung ventilation and causes less damage to the lungs. Whether simultaneous inflation of the mediastinum and abdomen during surgery has a significant impact on the respiratory and circulatory systems has not been reported. The purpose of this study was to evaluate the perioperative safety of this procedure.

\section{Materials and methods}

From April 2018 to October 2020, patients with esophageal malignant tumors were treated with SPIMSLE in the Fifth Affiliated Hospital of Sun Yat-sen University. The inclusion criteria were as follows: (1) pathologically confirmed malignant tumor and The preoperative $\mathrm{T}$ stages were T1b-T3; (2) functional tolerance of major organs and systems for radical surgery; (3) no other cancers; (4) no history of mediastinal surgery; The exclusion criteria were as follows: (1) cervical EC;(2) refusal of surgery.

This study was approved by the institutional review committee of our hospital. Written informed consent was obtained from each patient.

\section{Anesthesia}

Preoperative medication included intramuscular injection of atropine $0.01 \mathrm{mg} / \mathrm{kg}$. Anesthesia was induced by intravenous injection of midazolam $0.05 \mathrm{mg} / \mathrm{Kg}$, propofol $2 \mathrm{mg} / \mathrm{kg}$, muscle relaxant cis atracurium $0.15 \sim 0.25 \mathrm{mg} /$ $\mathrm{kg}$ and sufentanil citrate $0.1-0.3 \mathrm{ug} / \mathrm{Kg}$. Insert 7/7.5-FR single lumen catheter (Sheridan endotracheal catheter, Sher-I-Bronch). Do not use bronchial blockers. Mechanical ventilation after intubation (tidal volume 6-8 ml / kg; inspiratory time / expiratory time ratio: 1 / 1.5). Adjust the respiratory rate and do not use positive end-expiratory pressure. Anesthesia was maintained by continuous intravenous infusion of remifentanil $0.25 \mathrm{~g}-1.0 \mathrm{~g} / \mathrm{kg} / \mathrm{min}$, while inhaling air, oxygen and sevoflurane. After operation, the tube was extubated after the recovery of pharynx reflex, inhalation and ventilation. All intubation procedures are performed by experienced anesthesiologists.

\section{Surgical procedure}

The patients were ventilated with single-lumen endotracheal intubation under general anesthesia in the supine position; central venous pressure (CVP) was recorded by a central venous catheter in the right subclavian vein; and blood pressure was monitored by an indwelling arterial catheter in the right radial artery. As shown in Fig. 1, the operation was performed simultaneously in the mediastinum group and the abdominal cavity group. The mediastinum group entered the mediastinum through a cervical incision, and the abdominal group inserted a trocar into the abdominal cavity through five puncture points of the abdomen. The surgical incision, the location of the surgeon and the detailed surgical procedure are described in our recent report. [15, 17, 18].

The operation in the mediastinal group was performed as follows: first, access was gained through the cervical incision, and the cervical esophagus was freed, establishing a tunnel filled with carbon dioxide $\left(\mathrm{CO}_{2}\right)$ gas to create artificial mediastinal emphysema and obtaining a 


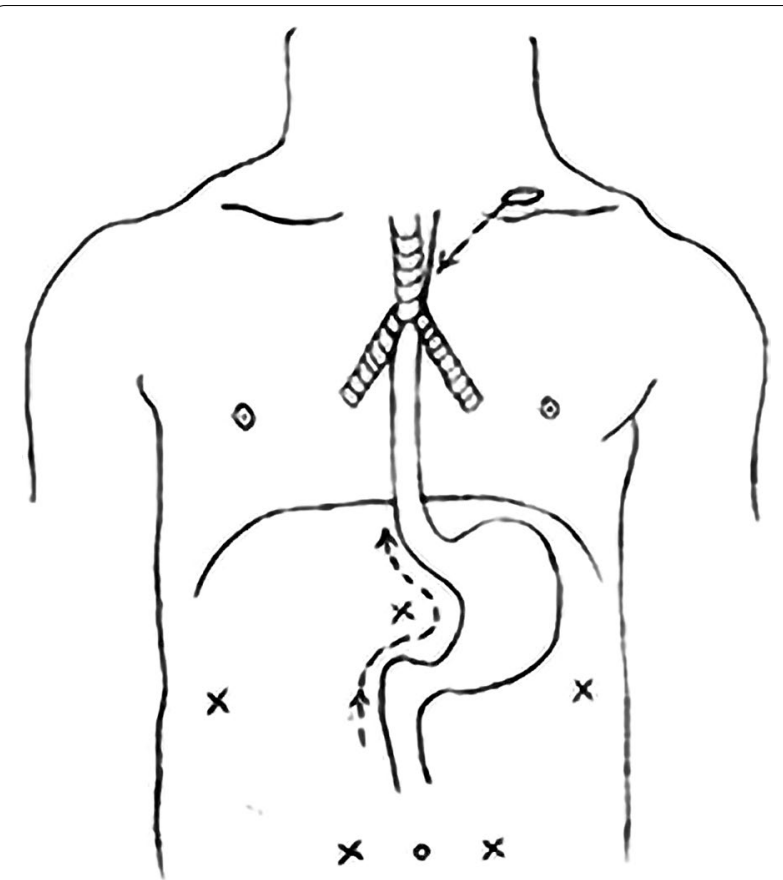

Fig. 1 A brief view of the surgical procedure. Enter the upper mediastinum through the left supraclavicular incision in the neck. Five trocars are placed into the abdominal cavity through the five intersecting positions in the picture. The arrow is the approximate direction of the operation

pressure of $10 \mathrm{mmHg}$. After we methodically tried various pressure gradients, when the mediastinal pressure was $10 \mathrm{mmHg}$, the operative field was clear, and the operative space was wide. Second, we continued to dissociate the upper and middle thoracic esophagus and dissected the lymph nodes in the thoracic region.

The operation in the abdomen group was performed as follows: the artificial pneumoperitoneum pressure was $12 \mathrm{mmHg}$, which is the conventional laparoscopic operative pressure. The stomach was dissociated, and the lymph nodes in the abdominal region of the esophagus were dissected. Next, the lower thoracic esophagus was dissociated through the diaphragmatic esophageal hiatus, and the surrounding lymph nodes were cleared. Finally, it penetrated the superior mediastinum. The air source was turned off, and inflation was stopped.

The esophagus was incised at the neck, the Tubular stomach was created, and the neck was anastomosed with the proximal esophagus through the esophageal bed. The neck and abdominal incisions were sutured.

\section{Observation parameters}

Heart rate (HR), invasive mean arterial pressure (MAP), central venous pressure (CVP), peak airway pressure (AP), end-expiratory $\mathrm{CO}_{2}$ partial pressure $\left(\mathrm{ETCO}_{2}\right)$, inhaled oxygen concentration $\left(\mathrm{FiO}_{2}\right)$ and tidal volume (TV) were continuously monitored and recorded during the operation. Arterial blood samples were collected for blood gas analysis at the following time points: $5 \mathrm{~min}$ before inflation of the mediastinum and abdomen (baseline); $1 \mathrm{~h}$ after inflation; 20 min after $\mathrm{CO}_{2}$ excretion; and $10 \mathrm{~min}$ after the operation. These data were collected from anesthetic records. At the same time, the operative duration, amount of bleeding, and A special event during the operation were recorded. Postoperative pathological data, postoperative complications, and postoperative hospital stay information were collected.

\section{Statistical analysis}

Continuous data are expressed as the mean \pm standard deviation (SD). The classified data are expressed as a percentage. During the operation, taking the pre-inflation data as the reference, the Welch test was used to analyze the numerical difference in each period after inflation. All statistical analyses were conducted using IBM SPSS version 25 (SPSS Statistics v25, IBM, Somers, NY, USA). When $P<0.05$, the result was considered significant.

\section{Results}

A total of 105 patients who underwent SPIMSLE from April 2018 to October 2020 were enrolled. The demographic and clinical characteristics of the 105 patients are summarized in Table 1 . The average age was $62.6 \pm 8.8$ years (range $42-84$ years), the percentage of vital capacity (VC) was 70.5-176.1\% (101.68 $\pm 23.00 \%)$, the percentage of forced expiratory volume to predicted value within $1 \mathrm{~s}$ (FEV1\%) was 67.9-163.3\% $(100.05 \pm 20.80 \%)$, and the average cardiac ejection fraction was $69.35 \pm 5.11$. The tumor sites included the upper chest $(n=14)$, middle chest $(n=56)$ and lower chest $(\mathrm{n}=35)$. The preoperative $\mathrm{T}$ stages were as follows: T1b, 36 patients; T2, 49patients; and T3, 20 patients. Comorbidities included COPD $(n=6)$, hypertension $(n=27)$ and diabetes $(n=9)$. Twenty-one of these patients received neoadjuvant chemotherapy.

\section{Intraoperative observation index}

There were no deaths within 30 days postoperatively. A total of 104 patients underwent SPIMSLE, and 1 patient underwent thoracotomy because of tracheal membrane injury during mediastinoscopy. Pleural rupture occurred in 5 cases, and the airway pressure increased immediately after pleural rupture, up to $4 \mathrm{cmH}_{2} \mathrm{O}$. The effect of tension pneumothorax on the operation could be avoided by suspending the operation for several minutes, properly reducing tidal volume and enlarging the scope of rupture. The average operative time was $186.7 \pm 43.9 \mathrm{~min}$, and the average intraoperative blood loss was $113.4 \pm 89.9 \mathrm{ml}$. 
Table 1 Patient demographics and clinical characteristics

\begin{tabular}{ll}
\hline Parameters & Number \\
\hline Age & \\
Average (range) & $62.6(42-84)$ \\
Gender & \\
Male & 75 \\
Female & 30 \\
Tumor location & \\
Upper thoracic segment & 14 \\
Middle thoracic & 56 \\
Lower thoracic & 35 \\
Biopsy pathology & \\
Squamous cell carcinoma & 99 \\
Adenocarcinoma & 1 \\
Small cell carcinoma & 1 \\
Sarcomatoid carcinoma & 1 \\
Neuroendocrine carcinoma & 3 \\
The preoperative T stages & \\
T1b & 36 \\
T2 & 27 \\
T3 & 20 \\
Concomitant disease & \\
COPD & \\
Hypertension & \\
Diabetes & \\
Atrial fibrillation & \\
Preoperative treatment & \\
Neoadjuvant chemotherapy & \\
Neoadjuvant radiotherapy & \\
\hline & \\
\hline
\end{tabular}

The field of view was clear during the operation, and the average number of lymph nodes dissected was $22.5 \pm 4.5$.

During the operation, the hemodynamics and respiratory movement indexes of 104 cases were monitored when $\mathrm{CO}_{2}$ was inflated into the mediastinum and abdomen synchronously, as shown in Table 2 . The data from 5 min before $\mathrm{CO}_{2}$ inflation were taken as the baseline, and there were significant differences in HR, MAP, CVP, Peak $\mathrm{AP}, \mathrm{ETCO}_{2}, \mathrm{PH}$, oxygenation index $(\mathrm{OI}$, the ratio of inhaled oxygen concentration to the partial pressure of oxygen) and partial pressure of $\mathrm{CO}_{2}\left(\mathrm{PaCO}_{2}\right)$ after inflation.

The variations in hemodynamics after inflation are shown in Fig. 2A.The changes in HR, MAP, and CVP are shown in Fig. 2B-D respectively. HR, MAP and CVP increased immediately after inflation and exhibited no significant change during inflation; however, these values also decreased significantly after gas shutdown, although they did not return to the baseline value. When the mediastinal pressure was $10 \mathrm{mmHg}$ and the pneumoperitoneum pressure was $12 \mathrm{mmHg}$, the average increase in $\mathrm{HR}$ was $16.5 \mathrm{bpm}$, the average increase in MAP was $18.6 \mathrm{mmHg}$, and the average increase in CVP was 8.2 $\mathrm{cmH} 2 \mathrm{O}$.

The changes in Peak AP, ETCO are shown in Fig. 3A-E respectively. Peak AP increased immediately after inflation (Fig. 3A). The average value of Peak AP was $22.8 \mathrm{cmH}_{2} \mathrm{O}$ during inflation, with a mean increase of $7.4 \mathrm{cmH}_{2} \mathrm{O}(P<0.05) 5 \mathrm{~min}$ after inflation. The average $\mathrm{ETCO}_{2}$ of $6.2 \mathrm{cmH}_{2} \mathrm{O}(P<0.05)$ increased 5 min after inflation (Fig. 3B), and the average value of $\mathrm{ETCO}_{2}$ was $41.0 \mathrm{mmHg}$ during inflation. Compared with the baseline value, the TV decreased significantly at $1 \mathrm{~h}$ after inflation $(P<0.05)$. The OI decreased sharply at $1 \mathrm{~h}$

Table 2 Changes in the respiratory and circulatory systems before and after inflation intraoperatively

\begin{tabular}{|c|c|c|c|c|c|c|c|}
\hline & \multirow[b]{2}{*}{$\begin{array}{l}5 \text { min before } \\
\text { inflation (baseline) }\end{array}$} & \multicolumn{4}{|c|}{ Inflatable stage } & \multirow[b]{2}{*}{$\begin{array}{l}20 \text { min after gas } \\
\text { shutdown }\end{array}$} & \multirow[b]{2}{*}{ Postoperative $10 \mathrm{~min}$} \\
\hline & & $5 \mathrm{~min}$ & $10 \mathrm{~min}$ & $20 \mathrm{~min}$ & $1 \mathrm{~h}$ & & \\
\hline$H R$ & $69.1 \pm 7.9$ & $87.6 \pm 15.5^{*}$ & $89.8 \pm 16.7^{*}$ & $90.2 \pm 16.5^{*}$ & $88.6 \pm 14.3^{*}$ & $77.9 \pm 12.8$ & $73.0 \pm 10.0$ \\
\hline MAP & $84.8 \pm 6.4$ & $103.4 \pm 14.8^{*}$ & $104.3 \pm 14.5^{*}$ & $97.9 \pm 14.5^{*}$ & $98.2 \pm 13.3^{*}$ & $90.6 \pm 6.2$ & $97.5 \pm 10.6$ \\
\hline CVP & $6.3 \pm 0.9$ & $14.5 \pm 1.5^{*}$ & $14.0 \pm 1.9^{*}$ & $14.0 \pm 1.6^{*}$ & $14.6 \pm 1.7^{*}$ & $10.1 \pm 1.6$ & $9.0 \pm 1.4$ \\
\hline Peak AP & $14.3 \pm 1.6$ & $21.7 \pm 3.2^{*}$ & $23.1 \pm 3.9^{*}$ & $23.0 \pm 4.5^{*}$ & $23.4 \pm 4.9^{*}$ & $15.5 \pm 2.4$ & $14.9 \pm 2.2$ \\
\hline $\mathrm{ETCO}_{2}$ & $33.4 \pm 3.4$ & $39.6 \pm 3.3^{*}$ & $40.5 \pm 5.8^{*}$ & $40.9 \pm 5.9^{*}$ & $43.1 \pm 5.6^{*}$ & $36.0 \pm 3.4$ & $34.6 \pm 2.8$ \\
\hline TV & $403.2 \pm 51.4$ & $395.6 \pm 49.2$ & $378.6 \pm 70.8$ & $379.5 \pm 50.0$ & $354.9 \pm 41.9^{*}$ & $365.8 \pm 42.5$ & $377.6 \pm 43.0$ \\
\hline Ol & $474.6 \pm 71.8$ & & & & $316.2 \pm 94.6^{*}$ & $360.6 \pm 80.1^{*}$ & $431.1 \pm 130.7$ \\
\hline $\mathrm{PH}$ & $7.38 \pm 0.04$ & & & & $7.26 \pm 0.06^{*}$ & $7.30 \pm 0.04^{*}$ & $7.34 \pm 0.03^{*}$ \\
\hline $\mathrm{PaCO}_{2}$ & $41.5 \pm 4.0$ & & & & $59.2 \pm 8.3^{*}$ & $52.5 \pm 4.5^{*}$ & $46.9 \pm 5.1^{*}$ \\
\hline Lac & $1.25 \pm 0.34$ & & & & $1.26 \pm 0.34$ & $1.27 \pm 0.35$ & $1.29 \pm 0.35$ \\
\hline
\end{tabular}

$H R$ heart rate; $M A P$ mean arterial pressure; $C V P$ central venous pressure; PeakAP peak airway pressure; $E T C O_{2}$ end-expiratory carbon dioxide partial pressure; $T V$ tidal volume; $\mathrm{Ol}$ oxygenation index; $\mathrm{PaCO}_{2}$ carbon dioxide partial pressure; Lac lactic acid level

${ }^{*}$ Compared with 5 min before inflation $(P<0.05)$ 

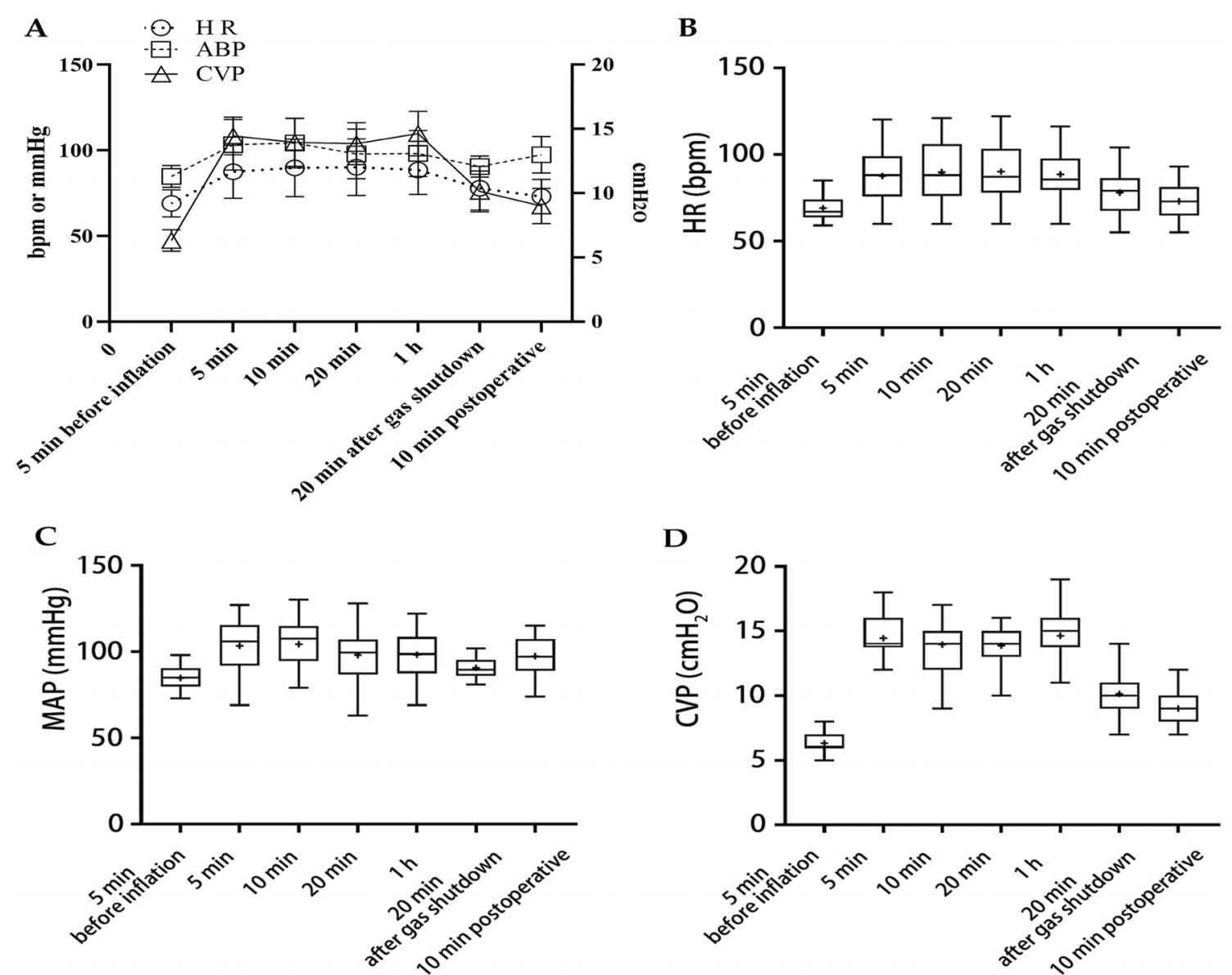

Fig. 2 Changes in circulatory parameters after intraoperative inflation. $5 \mathrm{~min}, 10 \mathrm{~min}, 20 \mathrm{~min}, 1 \mathrm{~h}$ are the post-inflatable time period. A Showed the variations in hemodynamics after inflation. B-D Showed the intraoperative changes of HR, MAP and CVP, respectively. HR, MAP and CVP increased significantly after aeration, and decreased steadily after gas shutdown

after inflation, with an average decrease of 158.6, gradually returning to close to the baseline value after gas shutdown (Fig. 3C). $\mathrm{PaCO}_{2}$ increased $17.7 \mathrm{mmHg}$ on average at $1 \mathrm{~h}$ after inflation (Fig. 3E). However, there was no significant change in the blood-gas lactic acid level before and after inflation $(\mathrm{P}=\mathrm{NS})$.

The incidence of postoperative complications is shown in Table 3. 90-day mortality was 0. Anastomotic fistula occurred in 9 cases (8.6\%), which were cured after vacuum sealing drainage (VSD) or routine drainage and adequate nutrition treatment. Among them, 9 cases (8.6\%) required management of pleural effusion, and all of these cases were treated by indwelling thoracic tube drainage. Postoperative chylous leakage occurred in 1 case $(0.9 \%)$. Approximately $300-400 \mathrm{ml}$ of a chylous fluid was drained. Enteral nutrition was stopped and then restored following parenteral nutrition and adequate drainage. Postoperative atelectasis occurred in 0 cases. Postoperative Pneumonia occurred in 8 cases
(7.6\%), which could be cured by anti-infective treatment. Arrhythmia occurred in 4 cases (3.8\%). Hoarseness was caused by recurrent laryngeal nerve injury in 19 cases (18.2\%); however, such injury of the recurrent laryngeal nerve was temporary and reversible. Voice training and an intravenous drip of ganglioside $40 \mathrm{mg} / \mathrm{d}$ were used for 3 days, and the patients gradually recovered within 1 to 2 months. Only 5 patients still had hoarseness 3 months after the operation. The visual analog scale (VAS) score of all patients in the first 3 days after operation was $4.09 \pm 0.57$.

\section{Discussion}

Transthoracic esophagectomy has become the standard procedure for EC because it enables extensive mediastinal lymphadenectomy [19-21]. However, postoperative pulmonary complications are a major problem in transthoracic surgery and the main cause of morbidity and mortality after thoracic surgery [22]. Non-transthoracic 


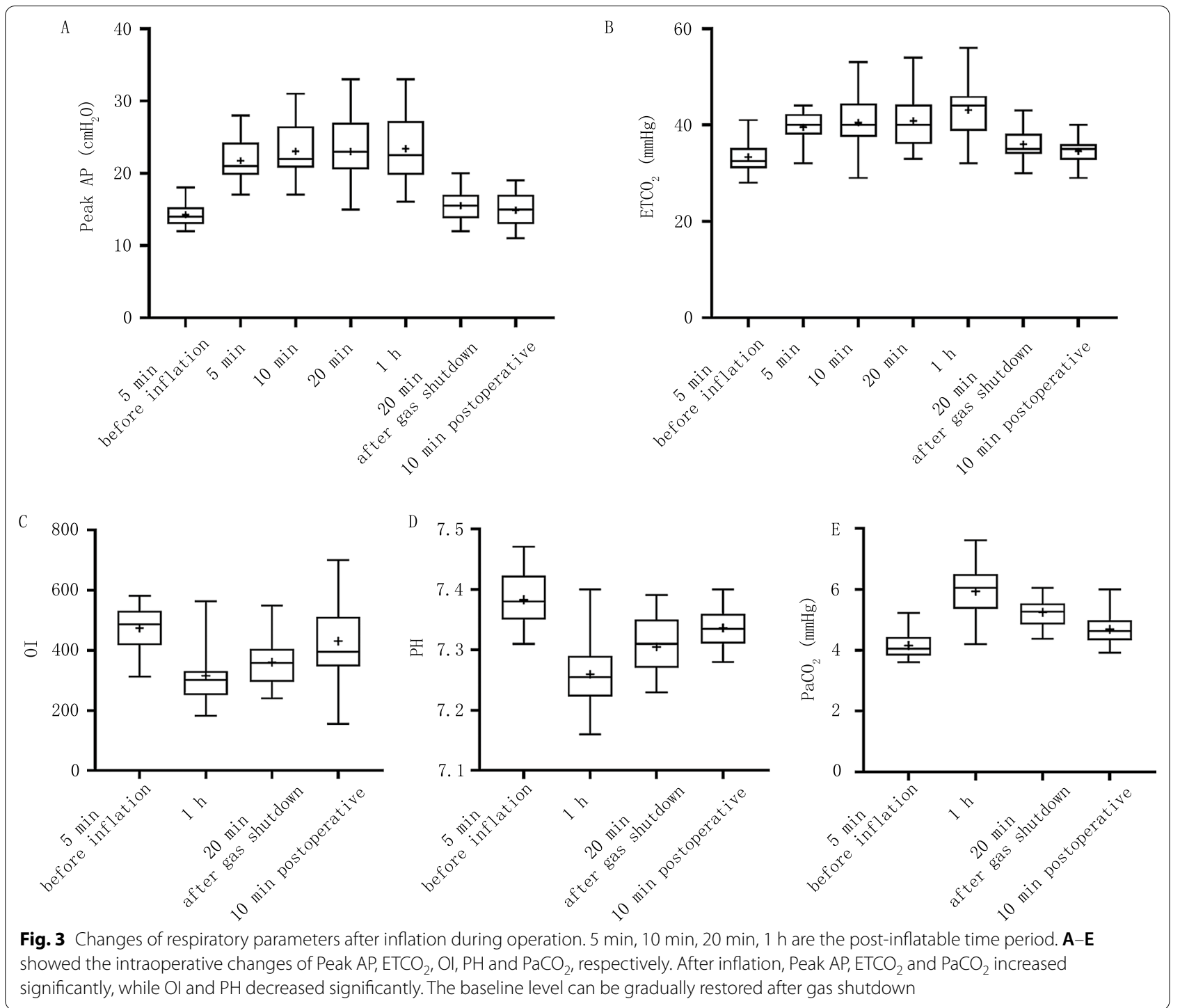

surgery, such as THE, is another option for MIE. Singleport mediastinoscopy-assisted transesophageal hiatal esophagectomy, which was developed by Fujiwara et al., has the advantages of less potential blood loss, a shorter operative time, and fewer cardiopulmonary complications [23]. Our team improved the procedure, which was administered to two groups at the same time, and the operative time was obviously shortened. Ye et al. conducted a retrospective comparative study and suggested that left recurrent laryngeal lymph node dissection is still a major technical challenge in MIE [21]. As we previously reported [15], we entered the mediastinum through the cervical incision, inflated it to form a mediastinal cavity, and easily cleared the lymph nodes along the left recurrent laryngeal nerve while also completely clearing the subcarinal lymph nodes. A retrospective study reported that the incidence of pneumonia and arrhythmia after transthoracic minimally invasive esophagectomy was $12.4 \%$ and $14 \%$, respectively [24]. In this study, we had a low incidence of postoperative pneumonia and arrhythmias.

In this study, we inflated the mediastinum and abdomen at the same time to provide a clear surgical field of vision (Fig. 4). Our average operative time was $240.7 \mathrm{~min}$, and the average intraoperative blood loss was $113.4 \mathrm{ml}$. Compared with thoracoabdominal endoscopy or traditional transthoracic open esophagectomy, our procedure reduced the operative and blood loss [25]. A retrospective study comparing one-lung ventilation and two-lung ventilation during MIE showed that the incidence of hypoxemia in the two-lung ventilation group was significantly lower than that in the one-lung ventilation group [26]. In our study, single-lumen endotracheal intubation was also used, but $\mathrm{CO}_{2}$ gas was filled into the 
Table 3 Perioperative observation index

\begin{tabular}{lll}
\hline Parameters & Quantity & (\%) \\
\hline Blood loss (ml) & $113.4 \pm 89.9$ & - \\
operative time(min) & $186.7 \pm 43.9$ & - \\
Conversion to thoracotomy & 1 & 0.9 \\
Postoperative hospital stay & $18.6 \pm 8.0$ & - \\
R0 resection & - & 100 \\
The 90-day mortality & 0 & 0 \\
Lymph node dissection & $22.5 \pm 4.5$ & - \\
Complication & - & - \\
Anastomotic fistula & 9 & 8.6 \\
Pleural effusion that needs to be treated & 9 & 8.6 \\
Chylothorax & 1 & 0.9 \\
Atelectasis & 0 & 0 \\
Pneumonia & 8 & 7.6 \\
Arrhythmia & 4 & 3.8 \\
hoarseness & 19 & 18.2 \\
Hoarseness at 3 months postoperatively & 5 & 4.8 \\
\hline
\end{tabular}
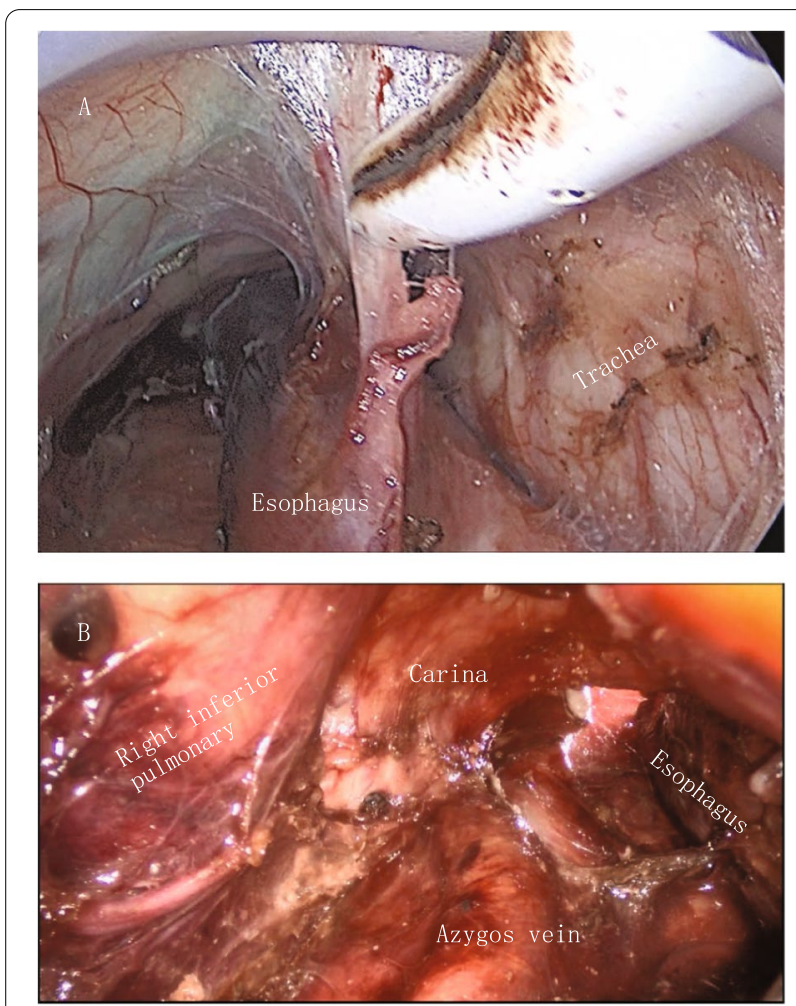

Fig. 4 Intraoperative visual field after inflation. A Transcervical view in the upper mediastinum in the artificial emphysema. $\mathbf{B}$ Transcervical view when the upper and lower mediastinum penetrates

mediastinum and abdomen simultaneously. Pneumoperitoneum and mediastinal emphysema, intraabdominal pressure, and $\mathrm{CO}_{2}$ absorption into the blood may cause a series of pathophysiological changes, affecting the respiratory and circulatory function of the patients and leading to postoperative cardiopulmonary complications. $\mathrm{CO}_{2}$ can increase the intra-abdominal and mediastinal pressures, elevate the diaphragm and compress the parietal pleura, thereby reducing lung compliance and increasing airway pressure, thus changing the pulmonary ventilation function and affecting intraoperative respiratory function $[27,28]$. Hypercapnia occurs after $\mathrm{CO}_{2}$ is absorbed into the blood and can induce a series of stress responses (such as stimulation of the sympathetic nervous system and the release of catecholamines), stimulate the cardiovascular system, and cause an increase in arterial pressure [29]. Secondly, increased intra-abdominal pressure and mediastinal pressure can compress large blood vessels, reduce venous reflux, increase systemic vascular resistance and increase CVP. At the same time, cardiac output is reduced, and the reflex causes sympathetic nerve excitation, which eventually increases arterial pressure and then affects circulatory function during the operation [29].

This study was a retrospective study of 104 patients who successfully completed SPIMSLE. During the operation, $\mathrm{CO}_{2}$ was infused into the mediastinum with a mediastinal pressure of $10 \mathrm{mmHg}$ and an intraperitoneal pressure of $12 \mathrm{mmHg}$. The HR, MAP and CVP increased significantly after inflation, but the values did not fluctuate and were within a safe and acceptable range during the inflation stage and gradually returned to the preinflation state after gas closure. No hypoxemia or respiratory inhibition was observed throughout the entire. After $\mathrm{CO}_{2}$ inflation, pH decreased, while $\mathrm{PaCO}_{2}$, peak $\mathrm{AP}$ and $\mathrm{ETCO}_{2}$ increased significantly after inflation, but these changes did not last long and returned to the normal level after the removal of $\mathrm{CO}_{2}$. Although $\mathrm{PaCO}_{2}$ increased significantly during the operation, the vital signs of most patients were stable, and there was no significant change in blood lactic acid levels, except for 2 patients who required adjustment in respiratory parameters to correct the elevated $\mathrm{PaCO}_{2}$. Currently, there is no clear definition of the acceptable elevation of $\mathrm{PaCO}_{2}$ in the clinic, so it is necessary to make a comprehensive judgment that also considers the vital signs of the patients. Although the OI decreased after inflation, it was still within a safe and acceptable range. With the deepening of the upper mediastinum and the lower mediastinum during the operation, the space of the operation was narrow, so it was necessary to control the effect of bilateral lung respiration on the mediastinal operation; moreover, the TV was artificially adjusted, so there was a significant difference between the TV at one hour after inflation and the baseline TV value. When dissociating the middle and lower esophagus during the operation, the lower 
mediastinal retractor should be used to lift the heart. In the study, 5 patients had hypotension or frequent premature ventricular contractions, which led to suspension of the operation. Notably, after waiting for a few minutes, the patients could continue the operation after their vital signs were stable. Therefore, when the mediastinal pressure and pneumoperitoneum pressure are $10 \mathrm{mmHg}$ and $12 \mathrm{mmHg}$, respectively, this can provide a clear operative field and sufficient operating space, and the operation is safe under standard operation conditions.

Minimally invasive surgery should be the first choice for patients with EC. Compared with MIE via a transthoracic approach, THE is considered to be less invasive and more tolerable, especially in patients with severe complications $[9,30]$. However, when the patient has comorbid diseases, such as severe chest adhesions, chest deformities, poor cardiopulmonary function, poor tolerance of one-lung ventilation, or a history of major right lung surgery $[15,31]$, transthoracic MIE is very difficult for surgeons and patients, and SPIMSLE may be a better choice.

In this study, we successfully completed the operation in 104 patients, there was no perioperative death, and the postoperative pathology confirmed that the R0 resection rate was $100 \%$. The incidence of postoperative anastomotic fistula was similar to that of MIE via the transthoracic approach $(5.0 \sim 12 \%) \quad[4,32]$. Compared with minimally invasive transthoracic esophagectomy [4], the incidence of postoperative hoarseness is still higher and needs to be improved There are still some limitations of this study. First, this study was retrospective, and we did not include patients with other EC operations as a control group. In subsequent research, a well-designed randomized controlled trial should be conducted to comprehensively evaluate the efficacy and safety of this new surgical method. Second, we did not evaluate the longterm quality of life of the patients after surgery. All these limitations should be addressed in future studies.

\section{Conclusion}

When the inflation pressures in the mediastinum and abdomen were $10 \mathrm{mmHg}$ and $12 \mathrm{mmHg}$, respectively, we safely completed surgery without respiratory and circulatory inhibition. In summary, our results show that our single-port inflatable mediastinoscopy with simultaneous laparoscopic radical resection of EC is technically safe and does not increase perioperative complications.

\footnotetext{
Abbreviations

EC: Esophageal cancer; MIE: Minimally invasive esophagectomy; THE: Transhiatal esophagectomy; SPIMSLE: Single-port inflatable mediastinoscopy simultaneous laparoscopic radical esophagectomy; CVP: Central venous pressure; $\mathrm{CO}_{2}$ : Carbon dioxide; HR: Heart rate; MAP: Mean arterial pressure; peak AP: Peak airway pressure; $\mathrm{ETCO}_{2}$ : End-expiratory $\mathrm{CO}_{2}$ partial pressure; $\mathrm{FiO}_{2}$ :
}

Inhaled oxygen concentration; TV: Tidal volume; Ol: Oxygenation index; VSD: Vacuum sealing drainage; VAS: Visual analog scale.

\section{Acknowledgements \\ None.}

\section{Authors' contributions}

HY and XW: drafting and revising manuscript. XL: acquisition. XG: analysis. HZ: interpretation of data. QC and XW: design and approval. All authors read and approved the final manuscript.

\section{Funding}

This study was supported by the Talents start-up funding of Sun Yat-sen University and National Key Research and Development Program of China (2018YFC0910600).

\section{Availability of data and materials}

The datasets used and/or analysed during the current study are available from the corresponding author on reasonable request.

\section{Declarations}

\section{Ethics approval and consent to participate}

The hospital ethics committee approval was granted of this article. Consent for publication was obtained from the paitent.

\section{Consent for publication}

Written informed consent was obtained from the patients for publication of this article.

\section{Competing interests}

All authors declare that they have no competing interests.

\section{Author details}

${ }^{1}$ Department of Thoracic Surgery, The Fifth Affiliated Hospital of Sun Yat-Sen University, 52 East Meihua Road, Xiangzhou District, Zhuhai 519000, Guangdong, China. ${ }^{2}$ Department of Anesthesia, The Fifth Affiliated Hospital of Sun Yat-Sen University, 52 East Meihua Road, Xiangzhou District, Zhuhai 519000, Guangdong, China.

Received: 20 June 2021 Accepted: 25 September 2021

Published online: 09 October 2021

\section{References}

1. Bray F, Ferlay J, Soerjomataram I, Siegel RL, Torre LA, Jemal A. Global cancer statistics 2018: GLOBOCAN estimates of incidence and mortality worldwide for 36 cancers in 185 countries. CA Cancer J Clin. 2018;68(6):394-424.

2. Lagergren J, Smyth E, Cunningham D, Lagergren P. Oesophageal cancer. The Lancet. 2017;390(10110):2383-96.

3. Van Daele D, Honore P, Collignon J, Polus M, Loly C, Mutijima E, et al. Comprehensive therapeutic strategy for localized esophageal cancer. Second part: interest of multimodal approaches with or without surgery. Rev Med Liege. 2017;72(4):168-74.

4. Luketich JD, Pennathur A, Awais O, Levy RM, Keeley S, Shende M, et al. Outcomes after minimally invasive esophagectomy: review of over 1000 patients. Ann Surg. 2012;256(1):95-103.

5. Luketich JD, Pennathur A, Franchetti Y, Catalano PJ, Swanson S, Sugarbaker DJ, et al. Minimally invasive esophagectomy: results of a prospective phase II multicenter trial-the eastern cooperative oncology group (E2202) study. Ann Surg. 2015;261(4):702-7.

6. Biere SS, Cuesta MA, van der Peet DL. Minimally invasive versus open esophagectomy for cancer: a systematic review and meta-analysis. Minerva Chir. 2009;64(2):121-33.

7. Sihag S, Kosinski AS, Gaissert HA, Wright CD, Schipper PH. Minimally invasive versus open esophagectomy for esophageal cancer: a comparison 
of early surgical outcomes from the society of thoracic surgeons national database. Ann Thorac Surg. 2016;101(4):1281-8; discussion 8-9.

8. Espinoza-Mercado F, Imai TA, Borgella JD, Sarkissian A, Serna-Gallegos D, Alban RF, et al. Does the approach matter? Comparing survival in robotic, minimally invasive, and open esophagectomies. Ann Thorac Surg. 2019;107(2):378-85.

9. Boshier PR, Anderson O, Hanna GB. Transthoracic versus transhiatal esophagectomy for the treatment of esophagogastric cancer: a metaanalysis. Ann Surg. 2011;254(6):894-906.

10. Omloo JM, Lagarde SM, Hulscher JB, Reitsma JB, Fockens P, van Dekken H, et al. Extended transthoracic resection compared with limited transhiatal resection for adenocarcinoma of the mid/distal esophagus: five-year survival of a randomized clinical trial. Ann Surg. 2007;246(6):992-1000; discussion-1.

11. Donohoe CL, O'Farrell NJ, Ravi N, Reynolds JV. Evidence-based selective application of transhiatal esophagectomy in a high-volume esophageal center. World J Surg. 2012;36(1):98-103.

12. Fujiwara H, Shiozaki A, Konishi H, Kosuga T, Komatsu S, Ichikawa D, et al. Single-port mediastinoscopic lymphadenectomy along the left recurrent laryngeal nerve. Ann Thorac Surg. 2015;100(3):1115-7.

13. Fujiwara H, Shiozaki A, Konishi H, Komatsu S, Kubota T, Ichikawa D, et al. Hand-assisted laparoscopic transhiatal esophagectomy with a systematic procedure for en bloc infracarinal lymph node dissection. Dis Esophagus. 2016;29(2):131-8.

14. Fujiwara H, Shiozaki A, Konishi H, Kosuga T, Komatsu S, Ichikawa D, et al. Perioperative outcomes of single-port mediastinoscope-assisted transhiatal esophagectomy for thoracic esophageal cancer. Dis Esophagus. 2017;30(10):1-8.

15. Wang X, Li X, Cheng H, Zhang B, Zhong H, Wang R, et al. Single-port inflatable mediastinoscopy combined with laparoscopic-assisted small incision surgery for radical esophagectomy is an effective and safe treatment for esophageal cancer. J Gastrointest Surg. 2019;23(8):1533-40.

16. Gan X, Wang X, Zhang B, Cheng H, Zhong B, Zhong H, et al. Lymphadenectomy along bilateral recurrent laryngeal nerves under single-incision mediastinoscopy. Ann Thorac Surg. 2020;109(6):e449-52.

17. Gan X, Zhong H, Li X, Wang X, Huo W, Wu T, et al. Mediastinal lymphadenectomy under laparoscopic assisted single-port inflatable mediastinoscopy through left neck approach. Transl Cancer Res. 2020;9(8):4976-81.

18. Wang X, Li X, Huo W, Cheng H, Zhang B, Zhong H, et al. The procedure of single-port inflatable mediastinoscopy and laparoscopic surgery for radical esophagectomy. Mediastinum. 2019;3:22.

19. Udagawa H, Ueno M, Shinohara H, Haruta S, Kaida S, Nakagawa M, et al. The importance of grouping of lymph node stations and rationale of three-field lymphoadenectomy for thoracic esophageal cancer. J Surg Oncol. 2012;106(6):742-7.

20. Tachimori Y, Ozawa S, Numasaki H, Matsubara H, Shinoda M, Toh Y, et al. Efficacy of lymph node dissection by node zones according to tumor location for esophageal squamous cell carcinoma. Esophagus. 2016;13:1-7.

21. Ye B, Zhong CX, Yang Y, Fang WT, Mao T, Ji CY, et al. Lymph node dissection in esophageal carcinoma: Minimally invasive esophagectomy vs open surgery. World J Gastroenterol. 2016;22(19):4750-6.

22. Lawrence VA, Cornell JE, Smetana GW. Strategies to reduce postoperative pulmonary complications after noncardiothoracic surgery: systematic review for the American College of Physicians. Ann Intern Med. 2006;144(8):596-608

23. Fujiwara H, Shiozaki A, Konishi H, Otsuji E. Transmediastinal approach for esophageal cancer: anew trend toward radical surgery. Asian J Endosc Surg. 2019;12(1):30-6.

24. Ben-David K, Tuttle R, Kukar M, Rossidis G, Hochwald SN. Minimally invasive esophagectomy utilizing a stapled side-to-side anastomosis is safe in the western patient population. Ann Surg Oncol. 2016;23(9):3056-62.

25. Kanekiyo S, Takeda S, Tsutsui M, Nishiyama M, Kitahara M, Shindo Y, et al. Low invasiveness of thoracoscopic esophagectomy in the prone position for esophageal cancer: a propensity score-matched comparison of operative approaches between thoracoscopic and open esophagectomy. Surg Endosc. 2018;32(4):1945-53.

26. Lin $M$, Shen $Y$, Wang $H$, Fang $Y$, Qian $C$, Xu S, et al. A comparison between two lung ventilation with $\mathrm{CO} 2$ artificial pneumothorax and one lung ventilation during thoracic phase of minimally invasive esophagectomy. J Thorac Dis. 2018;10(3):1912-8.

27. Nguyen NT, Anderson JT, Budd M, Fleming NW, Ho HS, Jahr J, et al. Effects of pneumoperitoneum on intraoperative pulmonary mechanics and gas exchange during laparoscopic gastric bypass. Surg Endosc. 2004;18(1):64-71.

28. Romero KJ, Trujillo MH. Spontaneous pneumomediastinum and subcutaneous emphysema in asthma exacerbation: the Macklin effect. Heart Lung. 2010;39(5):444-7.

29. Barczynski M, Herman RM. Influence of different pressures of pneumoperitoneum on the autonomic system function during laparoscopy. Folia Med Cracov. 2002;43(1-2):51-8.

30. Namm JP, Posner MC. Transhiatal esophagectomy for esophageal cancer. J Laparoendosc Adv Surg Tech A. 2016;26(10):752-6.

31. Peng JS, Kukar M, Mann GN, Hochwald SN. Minimally invasive esophageal cancer surgery. Surg Oncol Clin N Am. 2019;28(2):177-200.

32. Biere SSAY, van Berge Henegouwen MI, Maas KW, Bonavina L, Rosman C, Garcia JR, et al. Minimally invasive versus open oesophagectomy for patients with oesophageal cancer: a multicentre, open-label, randomised controlled trial. The Lancet. 2012;379(9829):1887-92.

\section{Publisher's Note}

Springer Nature remains neutral with regard to jurisdictional claims in published maps and institutional affiliations.
Ready to submit your research? Choose BMC and benefit from:

- fast, convenient online submission

- thorough peer review by experienced researchers in your field

- rapid publication on acceptance

- support for research data, including large and complex data types

- gold Open Access which fosters wider collaboration and increased citations

- maximum visibility for your research: over 100M website views per year

At BMC, research is always in progress.

Learn more biomedcentral.com/submissions 